IdeAs

Idées d'Amériques

$7 \mid 2016$

Cinéma et histoire dans les Amériques

\title{
La déclaration d'indépendance des États-Unis et les premières émancipations hispano-américaines de Terre-Ferme
}

\section{Clément Thibaud}

\section{(2) OpenEdition \\ Journals}

Electronic version

URL: https://journals.openedition.org/ideas/1628

DOI: 10.4000/ideas.1628

ISSN: 1950-5701

Publisher

Institut des Amériques

\section{Electronic reference}

Clément Thibaud, "La déclaration d'indépendance des États-Unis et les premières émancipations hispano-américaines de Terre-Ferme", IdeAs [Online], 7 | 2016, Online since 19 July 2016, connection on 18 October 2022. URL: http://journals.openedition.org/ideas/1628 ; DOI: https://doi.org/10.4000/ ideas. 1628

This text was automatically generated on 18 October 2022

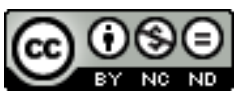

Creative Commons - Attribution-NonCommercial-NoDerivatives 4.0 International - CC BY-NC-ND 4.0 https://creativecommons.org/licenses/by-nc-nd/4.0/ 


\title{
La déclaration d'indépendance des États-Unis et les premières émancipations hispano-américaines de Terre-Ferme
}

\author{
Clément Thibaud
}

\section{Introduction}

1 The Independence of Spanish America, de Jaime Rodríguez 0. ${ }^{1}$, est aujourd'hui l'un des ouvrages les plus influents sur les indépendances hispano-américaines tant aux ÉtatsUnis que dans certains pays d'Amérique latine. Selon lui, ni l'indépendance américaine, ni 1789, ni les révolutions de Saint-Domingue, ni l'émancipation haïtienne n'auraient partie liée avec la création d'une dizaine de républiques dans le sud de l'Amérique. La Révolution espagnole de Cadix (1810-1812) s'imposerait comme la cause paradoxale et unique des mouvements émancipateurs dans les Indes espagnoles.

2 Pourtant, si l'on s'intéresse à l'espace bolivarien, soit grosso modo, la Colombie et le Venezuela actuels, le processus sécessionniste y suivit une trajectoire proche de celle qui conduisit à la création des États-Unis. Tout commence en 1811, avec la constitution d'États fédérés et la création de deux confédérations, celles des Provinces-Unies de Nouvelle-Grenade et du Venezuela. Ces gouvernements autonomes élirent des conventions pour se doter de chartes écrites. L'analogie avec la constitutionnalisation des treize colonies de l'Amérique du Nord et leur indépendance était patente. Ces lois fondamentales furent les premières $\mathrm{du}$ monde hispanique, avant même la promulgation de la constitution de Cadix. Sur le modèle de l'article VII de la charte du Massachusetts, toutes revendiquaient le droit de se doter du type de gouvernement qui conviendrait le mieux aux peuples, ouvrant la possibilité d'une abolition de la monarchie ${ }^{2}$. S'il n'était pas un modèle constitutionnel, le précédent nord-américain 
servit d'emblée à penser une souveraineté médiane, située entre celle du droit international et l'autonomie, dans le cadre du fédéralisme.

3 La constitutionnalisation des États provinciaux fit le lit de la république, mais contrairement au précédent des États-Unis, cela ne voulait pas dire que ces corps politiques renonçaient à jamais à retourner dans le giron de l'empire. Sauf, peut-être, au Venezuela, où la déclaration d'indépendance correspondit à des causes dont l'historiographie a simplifié la complexité en la rapportant à la pression qu'aurait exercée la Société patriotique de Caracas, supposément jacobine, sur le Congrès vénézuélien. Le point de bascule fut le rapport de l'ambassadeur du congrès vénézuélien auprès du président Madison, «dont le contenu produisit la motion sur la nécessité de l'Indépendance ${ }^{3}$ ». Les congressistes y virent un signal positif de la part des États-Unis, malgré le caractère dilatoire de la réponse du secrétaire d'État Monroe. S'il accueillait favorablement la création de nouvelles républiques au Sud, Monroe doutait de leur capacité à soutenir leur indépendance. L'espoir mis à tort dans le soutien de la grande République du Nord fut néanmoins l'ébranlement nécessaire pour que les Vénézuéliens prennent le risque de rompre avec le roi, l'Espagne et la monarchie.

Rédigée par l'avocat métis Juan Germán Roscio, la déclaration d'indépendance du Venezuela reprenait les termes de celle des États-Unis. Elle était, en réalité, une déclaration de guerre aux "gouvernements intrus» de l'Espagne. La confédération vénézuélienne, comme le congrès continental de 1776, y réclamait la reconnaissance de sa souveraineté par les autres nations et l'exercice des droits afférents : diplomatie, droit de déclarer la guerre et de faire la paix, commerce international. L'exorde final paraphrasait la déclaration de Jefferson et Franklin.

5 Mais le plus important était que, sans le dire expressément, ce texte créait de facto une république sans roi. Ce pas était gigantesque tant l'adhésion à la monarchie avait été exaltée dans toutes les cités de l'Amérique espagnole à la nouvelle de l'invasion napoléonienne et des abdications bourboniennes de 1808. La crainte que cette rupture inspirait était tout à fait justifiée comme le montre la suite des événements. Cités et provinces se soulevèrent pour résister au régime impie, à la « diablocratie ». C'est pour éteindre cette guerre civile commençante que le précédent nord-américain fut à nouveau mobilisé. Il s'agissait de montrer que la république était tout aussi divine que le royaume, contrairement à ce qu'affirmait partout la propagande royaliste. Il fallait mettre en scène le transfert de sacralité du roi au nouveau souverain, le peuple. Dans ce but, le gouvernement révolutionnaire publia un Manifeste que fait au monde la confédération du Venezuela. Rédigé également par Roscio, ce texte, avec beaucoup d'autres, s'appuyait sur les répertoires intellectuels du républicanisme exclusiviste pour justifier la compatibilité du nouveau régime avec la religion.

6 Que faut-il entendre par républicanisme exclusiviste? Une forme de pensée antimonarchique, fondée sur une conviction centrale : la royauté est mauvaise dans son principe et corruptrice dans ses effets ${ }^{4}$. Il ne s'agissait plus de condamner tel ou tel despote, sans égard pour la forme du régime où prospérait la tyrannie, mais tous les rois, en tous lieux. Ceux du passé, du présent et de l'avenir. Ce courant, jalonné par le Paradise Lost de Milton et le Common Sense de Paine, s'appuyait sur une certaine interprétation de l'histoire sacrée. Selon cette tradition, l'Ancien Testament fait de la royauté un châtiment que Dieu envoya aux juifs pour les punir de vouloir former une nation comparable aux autres ${ }^{5}$. Ce répertoire d'idées et de concepts, présent au cours 
des deux révolutions anglaises du XVIIe siècle et fondamental pour comprendre la Révolution américaine, devait se diffuser largement en Terre-Ferme.

7 Comment la rhétorique de la "République des Hébreux » a-t-elle pu accoster sur les rivages de l'Amérique du Sud? Certes, elle n'était pas inconnue de la tradition hispanique ${ }^{6}$. Mais dans sa modalité révolutionnaire, elle emprunta deux axes privilégiés : le premier, créole, parcourait un triangle dont les arêtes étaient Caracas, Carthagène et Bogotá ; le second, atlantique, reliait la capitale du monde républicain d'alors, Philadelphie - et la "catholique » Baltimore - avec les cités patriotes. Cette connexion hémisphérique du républicanisme éclaire la présence des références nordaméricaines lors de la création des premiers États sans roi du monde hispanique. Ce lien s'était affirmé avec l'ouverture du commerce impérial aux neutres en 1797. Les navires et les consuls de l'Union arrivèrent en force dans les ports de la Terre-Ferme, d'autant que la flotte de guerre espagnole avait été quasiment détruite au Cap SaintVincent (1797) et à Trafalgar (1805). Philadelphie abritait, de plus, de nombreux exilés $\mathrm{du}$ sous-continent. Ceux-ci y publièrent des ouvrages de réflexion politique dont beaucoup soutenaient la cause républicaine et les droits de l'homme. Santiago Puglia ouvrit un cycle promis à un grand avenir avec son Desengaño del hombre, publié en 1794. D'autres Hispano-américains hétérodoxes y traduisirent et publièrent des ouvrages mis à l'index ${ }^{7}$. C'est à partir de cette communauté d'exilés que les répertoires renouvelés de la "République des Hébreux" se diffusèrent en Terre-Ferme. Avec le temps, Philadelphie devint une capitale de la cause républicaine en Amérique espagnole, sous l'impulsion du journal de William Duane, Aurora. Le milieu local y observait d'ailleurs les événements hispano-américains avec attention. The Weekly Register de Baltimore fut l'un des premiers journaux à célébrer la déclaration d'indépendance vénézuélienne ${ }^{8}$.

Un nom revient souvent dans les ouvrages favoris de ce réseau intellectuel, celui de Thomas Paine. Les ouvrages du Britannique jalonnent en effet la progression de l'exclusivisme républicain. Il faut suivre la piste de Manuel García de Sena, dont le frère fut président de l'État de Barcelona, membre de la confédération vénézuélienne. García de Sena résidait à Philadelphie où il publia, dès 1811, la traduction de plusieurs textes du révolutionnaire britannique, sous le titre La Independencia de la Costa Firme justificada por Thomas Paine treinta años $\mathrm{ha}^{9}$. L'ouvrage comprenait la première partie de Common Sense, consacrée à la critique de la constitution anglaise. Il démontrait la sacralité du régime républicain par une lecture serrée des livres de Samuel. L'ensemble était complété par la Dissertation on the First-Principles of Government et les Dissertations on Government, the Affairs of the Bank and Paper Money. L'ouvrage comprenait aussi certains grands textes de la Révolution américaine, comme la Déclaration d'indépendance, les Articles de confédération, et différentes constitutions nord-américaines: Connecticut, New Jersey, Pennsylvanie, Virginie, et celle de l'Union. Ce livre circula et fut amplement cité ; il fut une source importante pour tous ceux qui pensaient que le cours de la Révolution américaine devait inspirer celui des émancipations hispanoaméricaines, notamment sur le plan constitutionnel.

\section{« Nouveau républicanisme » et indépendances croisées}

Un autre lien identificatoire unit les indépendances nord et sud-américaines; il passe par le baron de la Brède. « Montesquieu fit pour la fin du XVIIIe siècle ce que Machiavel 
avait fait pour son siècle, il fixe les termes dans lesquels le républicanisme devait être discuté $^{10} »$. Le jugement de Judith Shklar est valable pour l'Amérique hispanique au début du XIXe siècle. Car ce n'était pas tant le nom de Montesquieu qui faisait autorité que son œuvre lue au prisme de la Révolution américaine qui passionnait les patriotes qui imaginaient les premières institutions républicaines. Ceux-ci connaissaient l'histoire des États-Unis à travers les ouvrages écrits ou traduits en français par un ensemble d'auteurs liés par leur commune admiration pour l'Esprit des lois: Filangieri ou, plus tard, Destutt de Tracy. La référence au précédent nord-américain, lu au prisme du débat des Lumières sur la naissance des États-Unis, colore ainsi l'adoption du fédéralisme en Terre-Ferme. Aux yeux des jeunes gouvernements républicains, la gloire des États-Unis démontrait également que le régime antimonarchique était indiqué pour construire une société civile fondée sur la reconnaissance des droits naturels. La réussite économique de l'Union montrait les limites du républicanisme classique lorsqu'il opposait luxe et vertu.

Pour comprendre les liens entre les références à Montesquieu et aux États-Unis, on prendra pour guide la longue introduction qu'a donnée l'un des premiers républicains de la région, Miguel de Pombo, à l'une des traductions de la constitution américaine. Né à Popayán en 1779, Miguel appartenait à l'une des familles de propriétaires terriens et de négociants parmi les plus prospères de la Nouvelle-Grenade. En décembre 1811, sans doute, en plein débat sur le fédéralisme et la réforme de la première constitution monarchique du Cundinamarca, Miguel publia une traduction de la constitution américaine de 1787. Il fit précéder ce fort volume, exceptionnel à cette époque par son ampleur - 200 pages - d'un Discours préliminaire sur le système fédératif de 120 pages. Avec les écrits de Roscio ${ }^{11}$ et le Discours d'Angostura de Simón Bolívar, il s'agit de l'un des seuls plaidoyers explicites en faveur de la forme républicaine de gouvernement au cours des révolutions de la Terre-Ferme bolivarienne. Pombo y inscrit sa réflexion dans le cadre du "nouveau républicanisme». Ses réflexions se nourrissaient du débat français sur la Révolution américaine, dans la version qu'en donnèrent Raynal ou Brissot et Clavière, et repris par le compilateur espagnol Estala.

11 Sur le fond, Miguel de Pombo cherchait à prouver trois points à l'heure où l'indépendance $d u$ Venezuela avait ébranlé la Nouvelle-Grenade. Un: l'ère des républiques n'appartenait pas au passé classique. Deux: la Nouvelle-Grenade remplissait les critères de suffisance pour former une république indépendante et viable. Trois : l'Amérique était vouée à devenir le continent de la liberté.

Génies illustres de Washington, de Franklin, qui si justement avez reçu le titre de Législateurs du Nouveau Monde, écrivait-il, avec votre sagesse et vos vertus, vous avez illustré l'esprit et formé le cœur de vos Concitoyens, pour qu'ils ne succombent pas en défendant la glorieuse cause de l'indépendance! Les Américains du Sud invoquent vos noms en pareilles circonstances; venez au milieu de nous; enseignez-nous à aimer la modération, la frugalité, le désintérêt, l'union et autres vertus qui sont la base des Républiques; et montrez-nous la voie par laquelle, suivant les pas de vos chers compatriotes, nous réussirons à toucher le même point de prospérité ${ }^{12}$ !

Comme ses contemporains, Pombo n'inscrivait pas la révolution dans la perspective d'un "patriotisme créole ", à vrai dire introuvable, ni ne s'intéressait à la création d'une identité néo-grenadine. Pour lui, le projet de régénération républicaine concernait par définition toute l'Amérique. Il ne visait pas un peuple ou un territoire particulier, mais l'humanité entière. Les États-Unis préfiguraient une transformation 
universelle. Comme en attestent les efforts d'un Bolívar après la victoire militaire de 1824 pour confédérer les nouvelles républiques indépendantes, l'Amérique, dans son entier, figurait l'espace politique où s'inscriraient les progrès d'une liberté politique dont l'humanité se montrait désormais capable.

\section{NOTES}

1. J. E. RODRÍGuEZ O., The Independence of Spanish America, Cambridge, New York, Cambridge University Press, 1998 et J.E. RODRíGUEZ O., « Sobre la supuesta influencia de la independencia de los Estados Unidos en las independencias hispanoamericanas », Revista de Indias, janvier 2011, p. 691-714.

2. Acta de Federación de las Provincias Unidas de la Nueva Granada, 27.XI.1811, préambule.

3. Session du 2.VII.1811.

4. J. HANKINS, "Exclusivist republicanism and the non-monarchical republic ", Political Theory, $\mathrm{n}^{\circ} 38$ (4), 2010, p. 452-482.

5. I Samuel 8,6 .

6. G. ENTIn, La République en Amérique hispanique. Langages politiques et construction de la communauté au Rio de La Plata, entre monarchie catholique et révolution d'indépendance, thèse de l'École des Hautes Etudes en Sciences Sociales, Paris, 2011.

7. S. Puglia, El desengaño del hombre, Philadelphie, En la imprenta de Francisco Bailey, calle alta no. 116, 1794. M. HENRY, « Les premières publications révolutionnaires des exilés hispano-américains aux États-Unis », Transatlantica [En ligne], 2 | 2006, mis en ligne le 07 juillet 2006, Consulté le 2 juin 2016. URL : http ://transatlantica.revues.org/1146.

8. The Weekly Register, 14.IX.1811, $\mathrm{n}^{\circ} 2$.

9. La Independencia de la Costa Firme justificada por Thomas Paine treinta años ha. Extracto de sus Obras traducido del Inglés al Español por D. Manuel García de Sena, Philadelphie, T. y J. Palmer, 1811.

10. J. N. SHKLAR, « Montesquieu and the new republicanism », G. BOcK, Q. SKINNER et M. VIROLI (éd.), Machiavelli and Republicanism, Cambridge, Cambridge University Press, 1991, pp. 265-280, ici p. 265.

11. Patriotisme de Nirgua et abus des rois (1811); Le triomphe de la liberté sur le despotisme (1817).

12. Discours préliminaire..., op. cit., p. 36.

\section{AUTHOR}

\section{CLÉMENT THIBAUD}

Clément Thibaud, maître de conférences en histoire contemporaine, travaille sur l'histoire de l'Atlantique ibérique au XIXe siècle et l'histoire de la race à l'âge des révolutions dans l'espace caraïbe insulaire et continental. Il est l'auteur d'Un Nouveau Monde de républiques. L'invention des 
premiers États sans roi du monde hispanique (2016), La Academia de Charcas y la Independencia de América (1776-1809) (2011), La Majestad de los Pueblos (2010), Républiques en armes. Les armées de Bolivar dans la guerre d'Indépendance en Colombie et au Venezuela (2006) et coordonnateur de Couleurs, esclavages, libérations aux Amériques 1804-1860 (2013), L'Atlantique révolutionnaire, une perspective ibérique (1756-1865)(2013), Les empires atlantiques entre Lumières et libéralisme (1763-1865) (2009), Las revoluciones en el mundo atlántico: una perspectiva comparada (2006). 